\title{
Numerical simulation study on influencing factors to part-filling pillars' stability \\ Wanpeng HUANG ${ }^{1}$, Yanghui REN ${ }^{2}$, Lin GAO ${ }^{1}$
}

(1. College of Mining and Safety Engineering, Shandong University of Science and Technology, Qingdao 266590, China; 2. Shenhua Sciene and Technology Research Institute CO. LTD. , Beijing 100011, China)

\begin{abstract}
There are many factors that influence part-filling pillars' stability. In deep mining, the main factors are filling rate and the pillar's internal friction angle that can influence the pillar's plasticity area greatly in the process of filling pillar's deformation and destroyment. This paper takes filling rate and friction angle as the main variables to do the numerical simulation. It shows the relationship between the breadth of plasticity area with the fillings rate is power exponential function of adown concave shape. At the lower filling rate, the relationship with friction angle is power exponential function of up-concave shape which will changed into linearity filling rate increasing.
\end{abstract}

Keywords: part filling; plasticity area; filling rate; internal friction angle; numerical simulation.

\section{Preface}

In order to supporting the overlyings trata, reducing the rock caving and defor mation, we

fill material into the mined-out area. This method is called backfill mining. Stripe filling mining is relative to full filling. It's filling capacity and filling ratio is only part of produced coal. Only part of goaf is filled. The key strata of covering rock, backfill body, together with some surrounding rocks support the overlying strata, for fear of mining subsidence[1 3]. As shown in figure 1 .

\section{filling stripe}

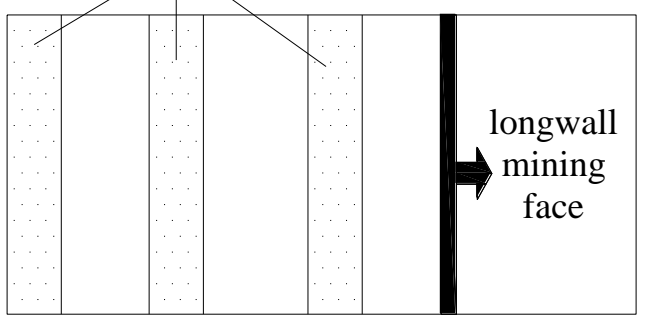

Fig.1: Part-filling schematic diagram

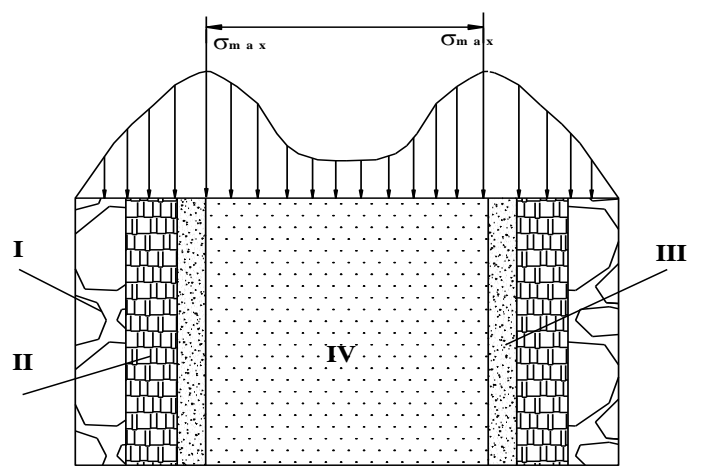

Fig.2 Distributing character of stress in fillings

The stress distribution of backfill body under the overlying strata is shown in figure 2[4] .According to the distortion and failure character in static test of cemented fill, the state of backfill body is from elastic to failure. This process should pass two kinds of state change: yielded state and plastic deformation. Therefore, for the equilibrium state of 
cemented fill, its behavior must be present: surface failure zone (I), plastic zone(II), yield zone(III) and elastic central area(IV)。

The failure process of backfill body is that failure zone gradually transform from the surface of cemented fill to the center. The result is that cemented fill is in plastic deformation state. Backfill body start unstable failure.

\section{Analysis of influencing factors on stability of filling body}

Study on the theory and practice suggest that the impact fact in stability of filling body may come down to three aspects: geological factors 、 mining factors and bands backfill mechanical properties.

\section{1 geological factors}

Geological factors mainly refer to mining depth, volume weight of overlying strata, angle of coal seam, surrounding rock(top, floor), in-situ rock stress and the influence of groundwater.

\section{2 mining factors}

Mining factors mainly refers to mining method, filling technology, width of backfill body and filling rate. It is proved that under the same filling rate, if we increase backfill body and the width of region which did not fill, the safety factor of backfill body will be improved. On the contrary, if backfill body and the width of region which did not fill decrease, backfill body effective support area (width of backfill body's elastic nuclear area ) will cut down, which may cause instability of backfill body.

\section{3 the mechanical properties of backfill}

The mechanical properties of includes elastic modulus, cohesion and internal friction angle. This is main factor affecting what influence the strength of backfill. It has a great influence on strength of backfill and its stability.

In the process of analysing the stability of backfill, we should calculate the width of plastic zone of backfill. When mining depth and height is determined, mechanical parameters of filling rate and backfill is become main factor affecting the width of plastic zone of backfill.

According to Kulun-Mohr strength theory, by criterion equation of coulomb $|\tau|=C+f \sigma=C+\sigma \tan \phi$ and the circle of limiting stress circle that meet the Coulomb criterion, We can know, in the condition of three-dimensional stress :

$\sigma_{1}=\frac{2 c \cos \varphi}{1-\sin \varphi}+\frac{1+\sin \varphi}{1-\sin \varphi} \gamma H$

In the above equation, the main factor what influence the strength of backfill has: cohesion $\mathrm{C}$ 、 internal friction angle $\mathrm{C}$, the average of overlying strata bulk density $\gamma$ and mining depth $H$. We can divided the formula (1) into two parts: $\sigma_{1}=\sigma_{1}^{1}+\sigma_{1}^{2}$. That is to say:

$\left\{\begin{array}{l}\sigma_{1}^{1}=\frac{2 c \cos \varphi}{1-\sin \varphi} \\ \sigma_{1}^{2}=\frac{1+\sin \varphi}{1-\sin \varphi} \gamma H\end{array}\right.$

In the above equation, in fact, $\sigma_{1}{ }^{1}$ is the strength limit when coal is not under lateral pressure, That is uniaxial compressive strength $\sigma_{\mathrm{c}}$. According to previous research ${ }^{[5]}$, when the mining depth is shallow, the contribution of $\sigma_{1}{ }^{1}$ and $\sigma_{1}^{2}$ to the strength limit of backfill $\sigma_{1}$ is the same. Compared with internal friction angle $\varphi$, cohesion has a greater influence on the $\sigma_{1}$ at this time. But when the mining depth is deep, the contribution of $\sigma_{1}^{2}$ become bigger. By the calculation formula $\sigma_{1}^{2}$, we can know that internal friction angle $\varphi$ has a great influence on $\sigma_{1}^{2}$ thus it has a strong influence on the strength limit of backfill. 


\section{Numerical simulation study on influence factors of backfill stability}

\section{1 the general geology of simulative coalface}

Taking a mine on the level of -780 working face in six mining area as the simulation object, the elevation of mining area upper limit is $-741 \mathrm{~m}$ and the lower limit is $-813.2 \mathrm{~m}$. The strike length is $1150 \mathrm{~m}$ and the average slope length is $180 \mathrm{~m}$. This coal mine belongs to the stability of coal seam, the average coal thickness is $1.62 \mathrm{~m}$ and the dip angle of coal seam is $10^{\circ}$. The immediate roof is the fourth layer of limestone and its average thickness is $5.97 \mathrm{~m}$. The uniaxial compressive strength is $84.31 \mathrm{Mpa}$; On the top of Taiyuan group NO.4 lime, there is siltstone that is gray and its thickness is $18.31 \mathrm{~m}$. The immediate roof is siltstone and its average thickness is $0.60 \mathrm{~m}$; the old roof is fine sandstone and its average thickness is $0.60 \mathrm{~m}$, uniaxial compressive strength is $60.68 \mathrm{MPa}$.

\section{2 establishment of model}

We used the FLAC3D simulation software to analyzing influence factors of the backfill.

Model of coal seam that exist in about $200 \mathrm{~m}$ below and top of rock for numerical calculation ${ }^{[6 \sim 7]}$. Making the weight of rocks above goaf as stress boundary condition on the upper boundary of the model. The size of uniform load $\mathrm{q}$ associates with lithology of overlying strata and buried depth, that is $q=\sum \gamma g h \cdot \gamma$ is bulk density overlying strata, $g$ is acceleration of gravity, $h$ is the thickness of overlying strata and take $800 \mathrm{~m}$.

Taking the model's length $500 \mathrm{~m}$ in $\mathrm{X}$ direction, $180 \mathrm{~m}$ in $\mathrm{Y}$ direction and $200 \mathrm{~m}$ in $\mathrm{Z}$ direction. The model consists of 59800 zones and 68859 gridpoints. Three dimensional calculation model is shown in Figure 3. There are 6 observation points in backfill and the roof.
We need to monitor the maximum unbalanced force of the model and observe the 6 observation point and its stress changes. Arrangement of measuring points as shown in figure 4 .

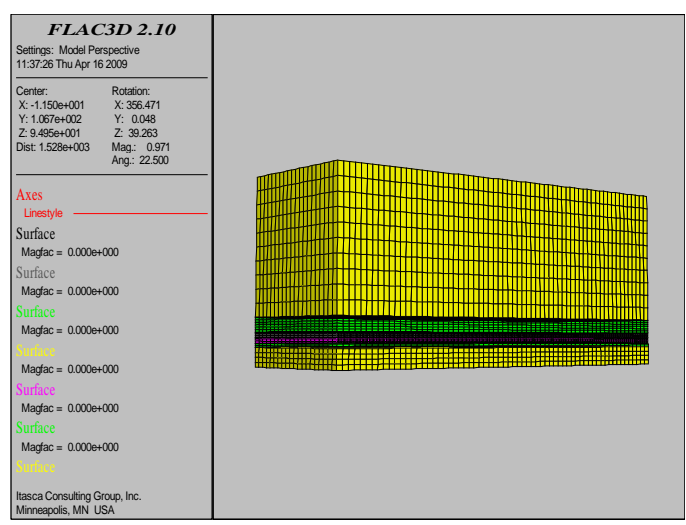

Fig.3: The model of numerical calculation

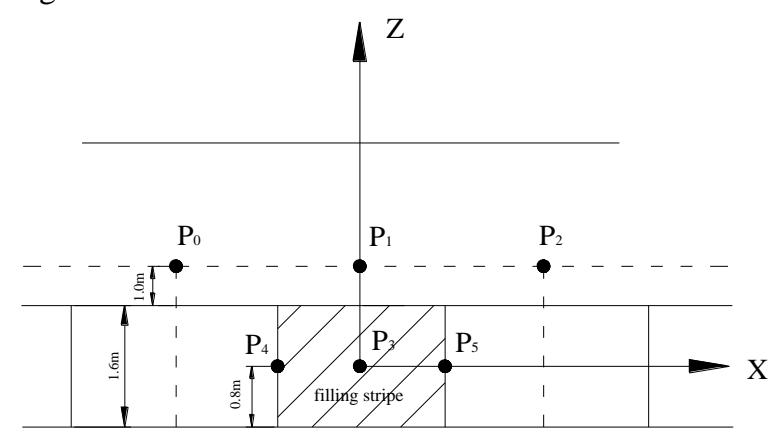

Fig.4: The schematic diagram of measuring points' arrangement

\section{3 schemes of numerical simulation}

Internal friction angle $\varphi$ becomes the

main factor influencing the ultimate strength of the filling pillars in its own mechanical parameters, for the mining depth is $-800 \mathrm{~m}$ in this simulation. So this simulation takes filling rate and as the main factors influencing the filling pillar's plasticity area to do this numerical simulation. The schemes of numerical simulation as Tab.1 
Table 1: Schemes of numerical simulation

\begin{tabular}{|c|c|c|c|c|c|c|c|c|c|}
\hline \multirow{2}{*}{$\begin{array}{l}\text { Package } \\
\text { number }\end{array}$} & \multirow{2}{*}{$\begin{array}{c}\text { Mining } \\
\text { height } \\
/ \mathrm{m}\end{array}$} & \multirow{2}{*}{$\begin{array}{c}\text { Mining } \\
\text { depth } \\
h / \mathrm{m}\end{array}$} & \multirow{2}{*}{$\begin{array}{c}\text { Breadth of not } \\
\text { filling area } \\
\mathrm{b} / \mathrm{m}\end{array}$} & \multirow{2}{*}{$\begin{array}{l}\text { Breadth of } \\
\text { filling } \\
\text { pillars } \\
a / \mathrm{m}\end{array}$} & \multirow{2}{*}{$\begin{array}{l}\text { Filling } \\
\text { rate } \\
\eta / \%\end{array}$} & \multicolumn{4}{|c|}{$\begin{array}{l}\text { friction angle of } \\
\quad \text { filling } \varphi /^{\circ}\end{array}$} \\
\hline & & & & & & 22 & 24 & 26 & 28 \\
\hline 1 & 1.6 & 800 & 25 & 30 & 54.5 & $\sqrt{ }$ & & & \\
\hline 2 & 1.6 & 800 & 25 & 30 & 54.5 & & $\sqrt{ }$ & & \\
\hline 3 & 1.6 & 800 & 25 & 30 & 54.5 & & & $\sqrt{ }$ & \\
\hline 4 & 1.6 & 800 & 25 & 30 & 54.5 & & & & $\sqrt{ }$ \\
\hline 5 & 1.6 & 800 & 25 & 50 & 66.7 & $\sqrt{ }$ & & & \\
\hline 6 & 1.6 & 800 & 25 & 50 & 66.7 & & $\sqrt{ }$ & & \\
\hline 7 & 1.6 & 800 & 25 & 50 & 66.7 & & & $\sqrt{ }$ & \\
\hline 8 & 1.6 & 800 & 25 & 50 & 66.7 & & & & $\sqrt{ }$ \\
\hline 9 & 1.6 & 800 & 25 & 70 & 73.7 & $\sqrt{ }$ & & & \\
\hline 10 & 1.6 & 800 & 25 & 70 & 73.7 & & $\sqrt{ }$ & & \\
\hline 11 & 1.6 & 800 & 25 & 70 & 73.7 & & & $\sqrt{ }$ & \\
\hline 12 & 1.6 & 800 & 25 & 70 & 73.7 & & & & $\sqrt{ }$ \\
\hline
\end{tabular}

\section{4 analysis of the simulation results}

Cutting out distributing nephogram of plasticity area both in the whole model and the filling pillars when the simulation calculation come to balance, taking the scheme 8 for example, see Fig 5.

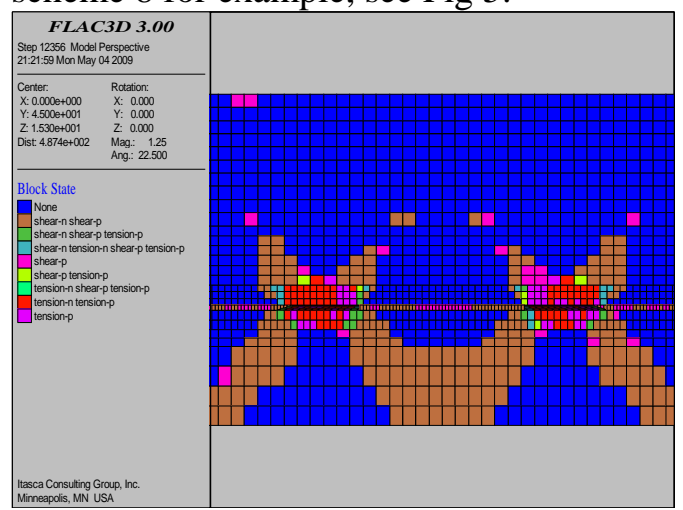

(a) plasticity area of the whole model area

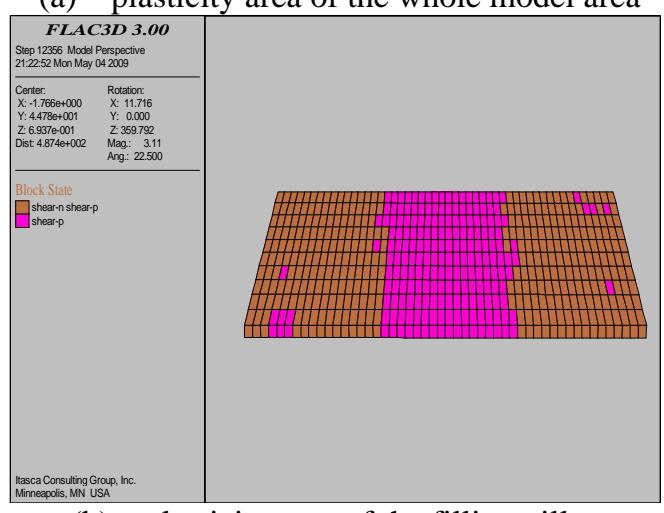

(b) plasticity area of the filling pillars

Fig. 5:The distributing nephogram of plasticity area in scheme 8
The distributing nephogram of plasticity area shows that influenced by the overlying load both side of the strip-filling appeared shear failure plasticity area. And the central part of the filling is the elastic core part which hasn't entered into the plastic stage. And under different scheme, the breadth of the plasticity area of strip-filling pillars is different, there is the average in table 2.

(1) the filling rate's influence on plasticity area

According to the chart, the proportion " $K$ " which the plasticity area taking up the whole filling pillar area decreases along with the filling rate $\eta$.The reason is that great filling rate of strip-filling leads to small load affecting transmit into filling pillars by the overlying rock, the interact with wide strip-filling is more closely, thus, the breath of the plasticity area can be controlled efficiently.

Selecting schemes which has different breath of filling pillar for data analysis under a certain friction angle, this paper get the regression curve between proportional coefficient " $K$ " and both breadth of filling " $a$ " and filling rate $\eta$, see Fig 6. 
Table 2: the plasticity area's breadth of strip-filling in different filling scheme

\begin{tabular}{|c|c|c|c|c|c|c|}
\hline $\begin{array}{c}\text { Simulation } \\
\text { scheme }\end{array}$ & $\begin{array}{c}\text { Breadth of not } \\
\text { filling area } \\
b / \mathrm{m}\end{array}$ & $\begin{array}{c}\text { Breadth of } \\
\text { filling } \\
\text { pillars } \\
a / \mathrm{m}\end{array}$ & $\begin{array}{c}\text { Filling } \\
\text { rate } \\
\eta / \%\end{array}$ & $\begin{array}{c}\text { friction } \\
\text { angle } \\
\varphi /{ }^{\circ}\end{array}$ & $\begin{array}{c}\text { Breadth of } \\
\text { Plasticity } \\
\text { area } \\
Y / \mathrm{m}\end{array}$ & $\begin{array}{c}\text { Proportional } \\
\text { coefficient } \\
K / \%\end{array}$ \\
\hline 1 & 25 & 30 & 54.5 & 22 & 13 & 43.3 \\
\hline 2 & 25 & 30 & 54.5 & 24 & 11 & 36.6 \\
\hline 3 & 25 & 30 & 54.5 & 26 & 9.5 & 31.7 \\
\hline 4 & 25 & 30 & 54.5 & 28 & 9 & 30 \\
\hline 5 & 25 & 50 & 66.7 & 22 & 18.5 & 37 \\
\hline 6 & 25 & 50 & 66.7 & 24 & 16 & 32 \\
\hline 7 & 25 & 50 & 66.7 & 26 & 15 & 30 \\
\hline 8 & 25 & 50 & 66.7 & 28 & 13.5 & 27 \\
\hline 9 & 25 & 70 & 73.7 & 22 & 17.2 & 24.6 \\
\hline 10 & 25 & 70 & 73.7 & 24 & 15.3 & 21.8 \\
\hline 11 & 25 & 70 & 73.7 & 26 & 14.5 & 20.7 \\
\hline 12 & 25 & 70 & 73.7 & 28 & 12.8 & 18.3 \\
\hline
\end{tabular}

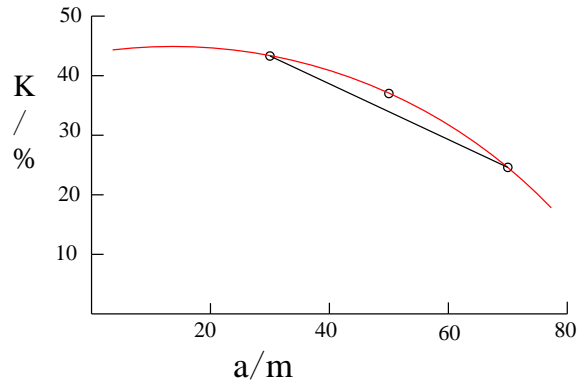

(a) scheme 1, 5, 9 relationship curve

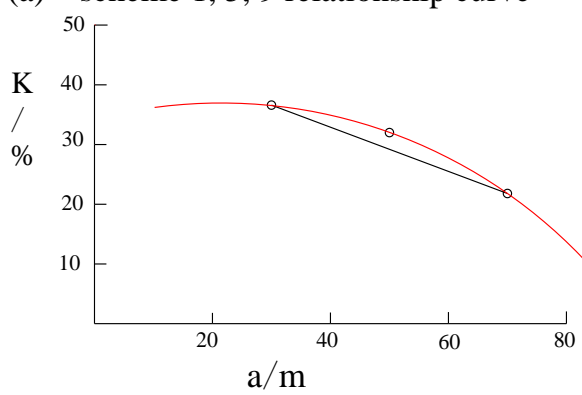

(b) scheme 2,6,1 relationship curve

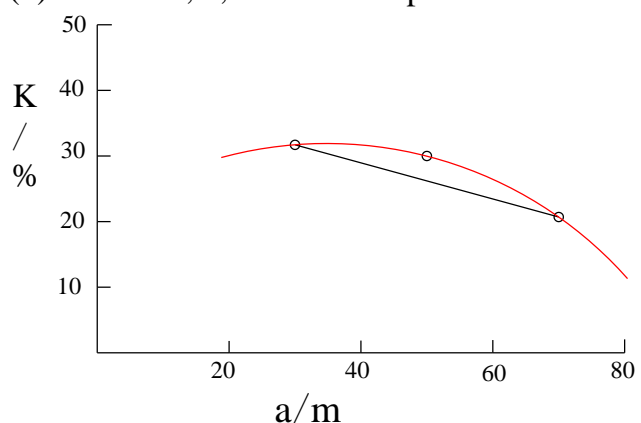

(c) scheme 3, 7, 11 relationship curve

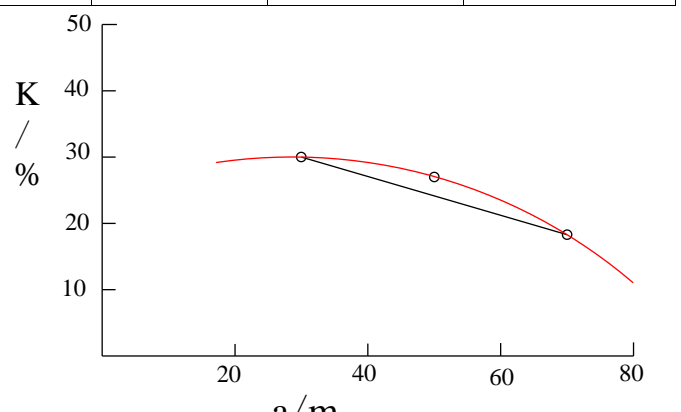

$\mathrm{a} / \mathrm{m}$

(d) scheme 4, 8, 12 relationship curve

Fig.6: The relationship between $\mathrm{K}$ and a

Obviously, it shows a power exponential function of adown concave shape about the proportion of filling pillars' plasticity area's breadth taking up the whole filling pillar area's breadth. The same to filling rate, and this proportion relationship will not change when friction angel changed.

(2)friction angle influence on thebreadth of plasticity area

As the chart shows, the ultimate strength increase as the friction angle increased, meanwhile, the breadth of filling pillar's plasticity area decreased .

Analyzing the breadth data of filling pillar's plasticity area in the scheme of same filling rate, get the relationship regression curve between proportion coefficient " $K$ " and friction angle $\varphi$, shown as Fig. 7. 


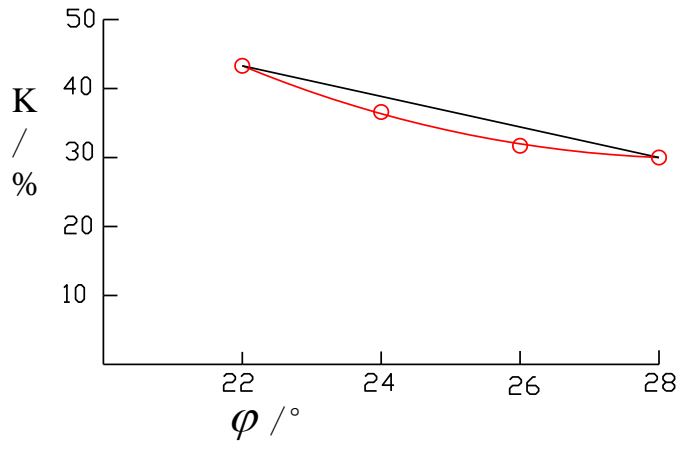

(a) scheme 1-4 relationship curve

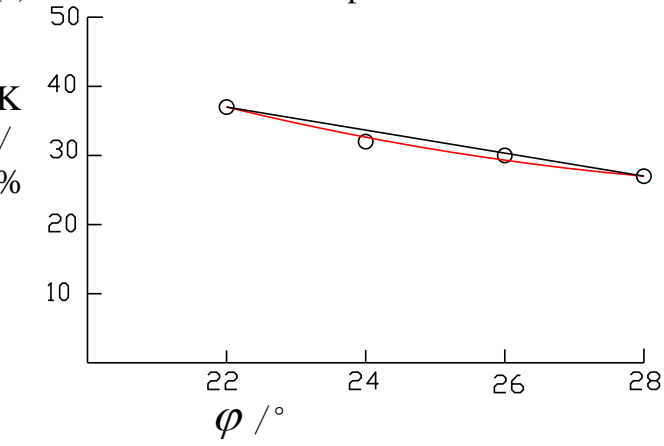

(b) scheme 5-8 relationship curve

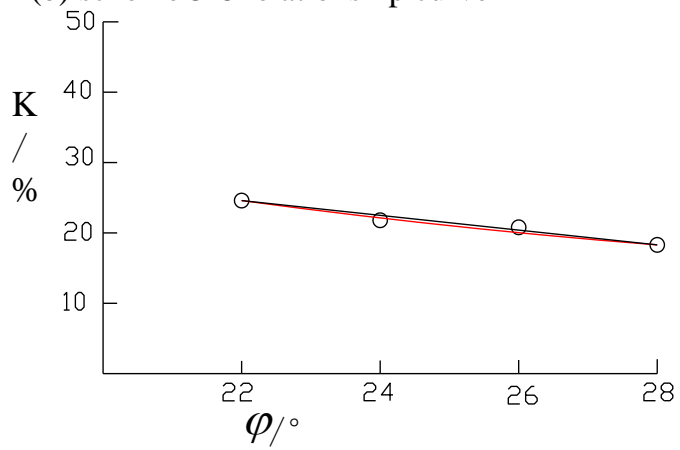

(c) scheme 9-12 relationship curve

Fig. 7: The relationship between $\mathrm{K}$ and $\varphi$

It is observed that the relationship between proportional coefficient $\mathrm{K}$ and internal friction angle $\varphi$ is power exponential function of up-concave shape in the scheme 1 to 4 . When filling rate reach to $66 \%$, the curved line segment and linear segment get close gradually and the linear segment slope is 1.6. When filling rate reach to $73.7 \%$, it can be seen the two curve substantially coincide in the scheme 9 to 12 which indicate the relationship between the pillar's plasticity area and internal friction angle is shows linear. The proportional coefficient is
1.05. So the internal friction angle has a significant impact on the breadth of plasticity area while the breadth of plasticity area is relative small; but with increase of breadth of plasticity area, the influence of internal friction angle to breadth of plasticity area is gradually smaller while the filling rate reaching $70 \%$, filling rate become the main factor affecting the breadth of plasticity area.

(3) analysis of filling body stability

Take the nephogram of horizontal and vertical stress of filling in scheme 8 as shown in Figure 8.

It is shows that vertical stress is $30-40 \mathrm{MPa}$ and horizontal stress is $20-25 \mathrm{MPa}$ which indicate that the horizontal stress of part-filling has been achieved larger values and side pressure coefficient has increase larger than upper part. The stress on filling body exceed its ultimate strength which result in generating plastic yield areas within limits of $13.5 \mathrm{~m}$ of its both sides. In the range of the elastic core part, the range of vertical stress is $20-30 \mathrm{MPa}$ and the range of horizontal stress is $10-15 \mathrm{MPa}$. According to the theoretical calculation, the actual vertical stress on the filling body full width is $1.26 \mathrm{GPa}$, so the stress on unit length is $\sigma_{0}=\sigma_{p} / a=1.26 / 50$ $=25.2 \mathrm{MPa}$, showing a good agreement with numerical simulation results and filling body is still in the elastic stage with great support ability.

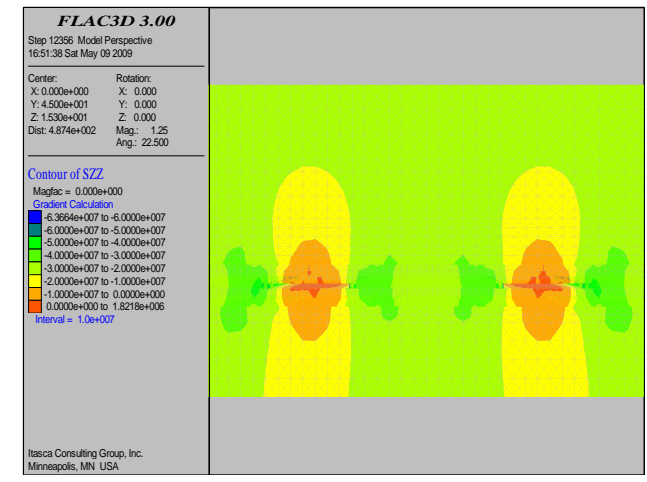

(a) The nephogram of vertical stress 


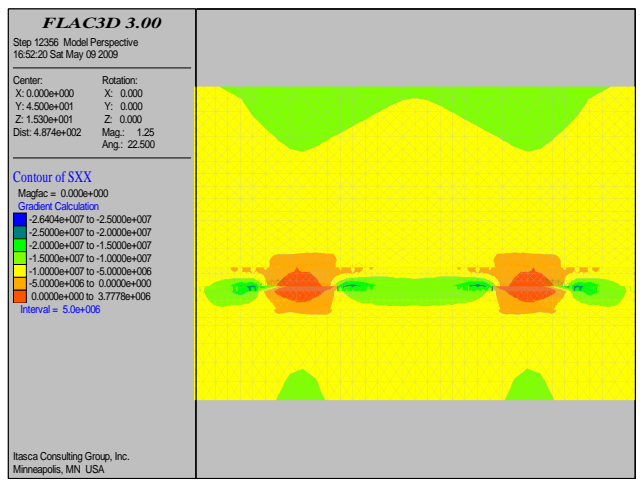

(b) The nephogram of horizontal stress

Fig.8: The nephogram of horizontal and vertical stress of filling in scheme 8

Take the nephogram of vertical stress of filling in scheme 8 as shown in Figure 9.

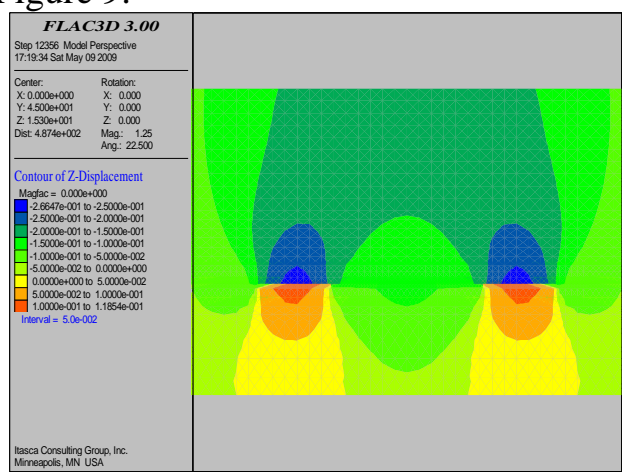

Fig.9 The nephogram of vertical displacement of filling

As Figure 9 shows, under overlying pressure, the displacement of core part of filling body is $5-10 \mathrm{~cm}$ and displacement of the plastic range is $10-15 \mathrm{~cm}$, which indicates that the strength of filling body meet the demands of control of overlying strata movement and the displacement is small, so the filling body can fully maintain its stability.

\section{Optimize the parameter of filling body scheme}

According to the above analysis, filling rate and the mechanical parameter of filling body (internal friction angle) are the major factors influencing the plastic range proportion. Due to the influence of these two parameters, the proportional region of plastic range in filling body width reach $18.3 \sim 43.3 \%$.

The increasing of the filling rate can reduce the width of plastic range obviously to increase effective support width of filling body(width of the elastic core part). The increasing of the filling rate must increase the cost of filling, reduce the profit of the coal mine enterprises, influence the promotion of part-filling pillars' technology applied in the field. According to research, the filling rate should be control under $70 \%$. The filling rate of scheme 5 8 is $66.7 \%$ and the controllable plastic range ratio is $27 \% \sim 37 \%$, with the requested of filling.

\section{Conclusions}

(1) The failure process of backfill body is that failure zone gradually transform from the surface of cemented filling body to the center. The worst result is the whole cemented fill is in plastic deformation state. Backfill body start failure .

(2) Filling rate and mechanical parameters of filling pillars are main factors which influenced the breadth of filling pillars' plasticity area in those influenced the stability of filling. In deep mining, friction angle $\varphi$ of filling has a great influence on ultimate strength of filling, then, affects the stability of filling.

(3) The relationship between the breadth of plasticity area with the fillings rate shows a power exponential function of adown concave shape. At a lower filling rate, the relationship with friction angle is power exponential function of up-concave shape which will changed into linearity filling rate increasing.

\section{References}

[1] XU Jia-lin, ZHU Wei-bing, LI Xing-shang. Study of the Technology of Partial-Filling to Control Coal Mining Subsidence[J]. Journal of Mining \& Safety Engineering. 2006, 23(1): 6-11. 
[2] XIE Wen-bing, SHI Zhen-fan, CHEN Xiao-xiang. Analysis of Surrounding Rock Activities in Partial Backfill Mining[J]. Journal of China University of Mining \&Technology. 2004, 33(2): 162-165.

[3] XU Jia-lin, YOU Qi, ZHUWei-bing. Theorectical study of strip-filling to controlm ining subsidence[J]. Journal of China Coal Society. 2007, 32(2): 119-122.

[4] Zhou Aimin. Cementation filling of mining flotsam[M]. Metallurgy Industry Press, 2007: 12-13, 37-40.

[5] Wang Xuchun, Huang Fuchang, Zhang Huaixin, Zhang Liangui. Discuss and improvement of A.H.Willson design formula[J]. Journal of China Coal Society, 2002, 27(6): 604-608.

[6] Xie Heping, Zhou Hongwei, Wang Jin'an. Application of FLAC to Predict Ground Surface Displacements Due to Coal Extraction and Its Comparative Aanlysis[J]. ChineseJournal of Rock Mechanics and Engineering. 1999, 18(4): 397-401

[7] LIU Peng-liang, HU Bing-nan, ZHANG Yu-jun. 3DNum erical Simulation Research on the Confirmation ofRationalM ining and PillarW idth in StripM ining[J]. CoalMiningTechnolog. 2006, 11(3): 1-3. 